\title{
Genomics-Informed Molecular Detection of Xanthomonas vasicola pv. vasculorum Strains Causing Severe Bacterial Leaf Streak of Corn
}

\author{
Michael J. Stulberg, ${ }^{1}$ Gem Santillana, ${ }^{1,2}$ David J. Studholme, ${ }^{3}$ Beth Kasiborski, ${ }^{1,2}$ Mary Ortiz-Castro, ${ }^{4}$ Kirk Broders, ${ }^{4}$ \\ Silvina Arias, ${ }^{5}$ Charles Block, ${ }^{5}$ Gary Munkvold, ${ }^{5}$ and John Rascoe ${ }^{1, \dagger}$ \\ ${ }^{1}$ Science and Technology, Plant Protection and Quarantine, Animal and Plant Health Inspection Service, U.S. Department of Agriculture, \\ Beltsville, MD, U.S.A. \\ 2 Department of Plant Pathology, North Carolina State University, Raleigh, NC, U.S.A. \\ ${ }^{3}$ Biosciences, University of Exeter, Exeter, U.K. \\ ${ }^{4}$ Department of Bioagricultural Sciences and Pest Management, Colorado State University, Fort Collins, CO, U.S.A. \\ ${ }^{5}$ Seed Science Center, Iowa State University, Ames, IA, U.S.A. \\ Accepted for publication 15 May 2019.
}

\begin{abstract}
Xanthomonas vasicola pv. vasculorum (syn. X. campestris pv. vasculorum) was initially identified as the causal agent of bacterial leaf streak of corn in South Africa. The pathovar vasculorum causes disease on sugarcane and corn, but a subset of these strains was noted for its increased disease severity in corn. This subset was reclassified as $X$. campestris pv. zeae in the early 1990 s and was found to have slightly different biochemical and genetic properties than isolates from sugarcane. There has been an emergence of X. campestris pv. zeae-like strains of $X$. vasicola pv. vasculorum in both the United States and Argentina since 2010. We performed whole genome sequencing on U.S. isolates to confirm their identity. Informed by comparative genomics, we then developed specific TaqMan qPCR and loop-mediated isothermal amplification (LAMP) assays for the detection of this specific subset of $X$. vasicola pv. vasculorum strains. The qPCR 4909 assay was tested

against 27 xanthomonads (diverse representation), 32 DNA extractions from corn leaves confirmed as positive or negative for the bacterium, 41 $X$. vasicola pv. vasculorum isolates from corn in the United States and Argentina, and 31 additional bacteria associated with corn, sugarcane, or sorghum. In all cases the assay was shown to be specific for the $X$. vasicola pv. vasculorum isolates that cause more severe disease on corn. We then tested the LAMP 166 assay against the 27 xanthomonads and 32 corn leaf DNA samples, and we found this assay was also specific for this subset of $X$. vasicola pv. vasculorum isolates. We also developed a live/dead cells distinction protocol using propidium monoazide prior to DNA extraction for analyzing seed washes using these assays. These two detection assays can be useful for both diagnosticians and researchers to specifically identify the $X$. vasicola pv. vasculorum isolates that cause more severe symptoms on corn.
\end{abstract}

Bacterial leaf streak of corn, caused by Xanthomonas vasicola pv. vasculorum, emerged within the last decade on two new continents in addition to the country of South Africa, where it was described in the late 1940s. In the 1950s, South African officials observed that the disease caused little damage and did not affect plant development, and it was therefore not regarded as economically important (Coutingo and Wallis 1991). In the late 1980s in South Africa, however, bacterial leaf streak became a greater cause of concern as it frequently occurred both at breeding stations and in farming areas, leading to the withdrawal of a commercial maize variety due to susceptibility to the disease (Coutingo and Wallis 1991). Recently,

†Corresponding author: J. Rascoe; John.Rascoe@aphis.usda.gov

Funding: Funding was provided in part by the Farm Bill. This research was supported in part by the intramural research program of the U.S. Department of Agriculture, Animal and Plant Health Inspection Service. The findings and conclusions in this preliminary publication have not been formally disseminated by the U.S. Department of Agriculture and should not be construed to represent any agency determination or policy. D. J. Studholme acknowledges the support of COST Action CA16107 EuroXanth, supported by COST (European Cooperation in Science and Technology).

*The $\boldsymbol{e}$-Xtra logo stands for "electronic extra" and indicates that two supplementary tables are published online.

The author(s) declare no conflict of interest.

This article is in the public domain and not copyrightable. It may be freely reprinted with customary crediting of the source. The American Phytopathological Society, 2019. the disease was found in the United States, Argentina, and Brazil (Korus et al. 2017; Leite et al. 2019; Plazas et al. 2018; E. Sagata et al., unpublished data). The U.S. Department of Agriculture issued a statement in 2016 indicating that it did not consider the disease to be of quarantine significance for domestic or international trade (Boehland 2016).

A challenge to corn growers is identifying the disease for proper disease management. Symptoms of bacterial leaf streak occur on leaves of field (dent) corn, sweet corn, and popcorn, appearing as yellow-brown lesions with wavy margins following leaf veins (Coutingo and Wallis 1991; Lang et al. 2017). Late stage symptoms can be confused with a fungal disease of corn, gray leaf spot, caused by Cercospora zeae-maydis. Growers benefit from quick and accurate identification of disease-causing agents to make the most efficient management decisions, as fungicide applications have no effect on bacterial leaf streak. Additionally, not all $X$. vasicola pv. vasculorum strains cause severe disease in maize, making it important to identify those strains more likely to warrant a management decision.

Identifying $X$. vasicola pv. vasculorum can be challenging because it has been isolated from multiple hosts and has a complex taxonomic history. There are differences in disease severity among isolates on certain hosts, e.g., corn and sugarcane, but possibly not enough biochemical and physical differences to warrant different pathovar designations (Qhobela et al. 1990). A subset of isolates, originally classified as $X$. campestris pv. vasculorum and causing relatively severe symptoms on corn, were subsequently called $X$. campestris pv. zeae and could be differentiated from sugarcane isolates by restriction fragment length polymorphism, suggesting genomic differences between the strains (Coutingo and Wallis 
1991; Qhobela and Claflin 1992; Qhobela et al. 1990). Recent wholegenome analysis showed that these differences led to distinct phylogenetic clustering of corn isolates compared with isolates from sugarcane (G. Wu et al., unpublished data). Sugarcane isolates can still be found on corn, especially if the two crops are grown in the same geographical area, but it is of greater concern to growers if the strains causing severe symptoms on corn are present (Coutingo and Wallis 1991). The reclassification of Xanthomonas by Vauterin et al. (1995) subdivided $X$. campestris pv. vasculorum into two new taxa: $X$. vasicola $\mathrm{pv}$. vasculorum and $X$. axonopodis vasculorum. Vauterin's description of new taxon $X$. vasicola pv. vasculorum was invalid, as it did not designate a pathotype strain. Nevertheless, most authors have subsequently followed Vauterin's nomenclature, and a recent review of the $X$. vasicola species taxonomy presents an updated formal description of the pathovar $X$. vasicola pv. vasculorum (Studholme et al. 2019). It should also be noted that Vauterin's taxonomic studies did not include $X$. campestris pv. zeae corn strains but did use a corn isolate of X. vasicola pv. vasculorum (LMG 8284 or NCPPB 206) that was not representative of the bacterium being described as $X$. campestris pv. zeae (Vauterin et al. 1992); thus the taxonomic position of $X$. campestris pv. zeae corn strains was not addressed during the Vauterin et al. (1995) reclassification.

Here, we sequenced the whole genome of strain SAM119. This strain was historically classified as $X$. campestris pv. zeae and more recently was proposed as the type strain of $X$. vasicola $\mathrm{pv}$. vasculorum (Lang et al. 2017; Studholme et al. 2019). We compared it to genomes of nine $X$. vasicola isolates from multiple hosts, with the goal to design real-time PCR and loop-mediated isothermal amplification (LAMP) assays for fast and accurate detection of the strains known to cause more severe disease on corn. We designed two assays, a field deployable assay (the LAMP assay) for bacterial streaming samples taken from leaf lesions, and a more sensitive real-time PCR assay to detect $X$. vasicola pv. vasculorum in total DNA extracts from leaf material or seed wash. A third goal was to develop an assay that could be used to test seeds directly and distinguish live versus dead cells, which led to a propidium monoazide (PMA) protocol prior to seed wash DNA extraction and detection.

\section{MATERIALS AND METHODS}

Bacterial strains and samples. Twenty-seven strains representing a variety of Xanthomonas spp. were obtained from the National Collection of Plant Pathogenic Bacteria (NCPPB) to evaluate the specificity of the real-time PCR and LAMP assays. Strain identity was confirmed by amplifying and sequencing at one or more of the following genes: gyrB, atpD, and dnaK (Ah-You et al. 2009; Parkinson et al. 2007). Specificity testing also included Dickeya solani and Ralstonia solanacearum strains plus 32 DNA extracts from corn leaf samples with bacterial leaf streak-like symptoms. Presence or absence of $X$. vasicola pv. vasculorum in these samples was determined by PCR, Sanger sequencing, and phylogenetic analysis as part of confirmatory diagnostics by the APHIS-PPQ-S\&T-CPHST-Beltsville laboratory. The real-time PCR assay was tested against a second collection of bacterial organisms. This collection consisted of 72 bacterial organisms isolated from corn, sorghum, or sugarcane, with $41 X$. vasicola $\mathrm{pv}$. vasculorum isolates from corn representing multiple U.S. states and Argentina.

Genome sequencing, assembly, and comparison. Four Xanthomonas genomes were sequenced, three maize isolates originating from U.S. states (Xvv 645, Xvv 681, and Xvv 715) and the strain SAM119 isolated from maize in South Africa (all $X$. campestris pv. zeae-like strains). The U.S. maize isolates were collected in 2016 from Kansas (Xvv 645), Colorado (Xvv 681), and Minnesota (Xvv 715).

DNA was extracted from overnight cell cultures grown in nutrient agar broth using a CTAB method for strains Xvv 645, Xvv 681, Xvv
715, and a Blood \& Cell Culture DNA Maxi Kit (Qiagen) for strain SAM119. DNA was fragmented to roughly $550 \mathrm{bp}$ sizes using a M220 sonicator (Covaris, Woburn, MA) and prepared using the TruSeq Nano DNA Library Prep kit (Illumina, San Diego, CA) for 300-bp paired end sequencing on a MiSeq platform (Illumina). For PacBio sequencing, DNA from SAM119 was submitted to the University of Maryland School of Medicine, Institute for Genome Sciences, where it underwent long-insert PacBio library preparation before PacBio RS II sequencing.

Genomes were assembled using SPAdes 3.10.1 (Bankevich et al. 2012) and Pilon v1.22 (Walker et al. 2014). Draft genomes were annotated with GeneMarkS+ using the National Center for Biotechnology Information (NCBI) Prokaryotic Genome Annotation Pipeline. Raw sequencing files were deposited to the Sequence Read Archive and assembled genomes deposited to GenBank: Xvv 645 (SRR8239205, PYJJ00000000), Xvv 681 (SRR8240252, PYJK00000000), Xvv 715 (SRR8240255, PYJL00000000), and SAM119 (name: Xv 416, SRA PacBio SRR8240386 and Illumina SRR8240385). Genomes were obtained from GenBank via the NCBI web portal for phylogenetic analysis using REALPHY (Bertels et al. 2014).

The genome of the $X$. vasicola pv. vasculorum pathotype strain SAM119 (CP028127) (Lang et al. 2017) was compared with $X$. vasicola pv. vasculorum strain NCPPB 206 (AKBM01000000), $X$. vasicola pv. vasculorum strain NCPPB 1326 (AKBK01000000), $X$. vasicola strain NCPPB 1396 (JSBX01000000), X. vasicola strain NCPPB 1241 (JSBV01000000), X. campestris pv. musacearum strain NCPPB 2005 (AKBE01000000), X. campestris pv. arecae strain NCPPB 2649 (JSBP01000000), and X. oryzae pv. oryzae strain MAFF 311018 (NC_007705) using the Seq_diff program (Stulberg et al. 2015) to identify sequences unique to SAM119. Unique regions were screened in local BLAST (Altschul et al. 1990) searches using Geneious software v10 (Kearse et al. 2012) and compared with other $X$. vasicola genomes for inclusivity and exclusivity. For visualization, alignments of raw Illumina reads to SAM119 were performed using BWA-mem ( $\mathrm{Li}$ and Durbin 2009) and SAMtools ( $\mathrm{Li}$ et al. 2009) prior to using the Integrative Genomic Viewer v2.4.19 (Thorvaldsdóttir et al. 2013). Primers and probe for the TaqMan assay were designed using Geneious software v10 and the Integrated DNA Technologies (IDT, Coralville, IA) website, with design parameters targeting a $\mathrm{GC}=45$ to $60 \%, \mathrm{Tm}=$ $60^{\circ} \mathrm{C}$, and primer length $=18$ to $26 \mathrm{bp}$. Primers for the LAMP assay were designed using PrimerExplorerV4.

Real-time PCR. Two labs participated in the validation of the TaqMan real-time PCR assay: the method development lab and the testing lab. In the method development lab, real-time PCR assays were performed in a $25 \mu \mathrm{l}$ volume with $1 \times$ PCR buffer (Invitrogen, Waltham, MA), Platinum Taq polymerase (Invitrogen) $1.25 \mathrm{U}$ per reaction, $0.24 \mu \mathrm{M}$ each of primers 4909_F and 4909_R, $0.12 \mu \mathrm{M}$ of probe 4909_probe, $3 \mathrm{mM} \mathrm{MgCl} 2$ (Invitrogen), $0.3 \mathrm{mM}$ of dNTPs (Sigma Aldrich, St. Louis, MO), $50 \mathrm{nM}$ ROX Reference Dye (Invitrogen), and $2 \mu \mathrm{l}$ of template DNA. Reactions were performed in a QuantStudio 7 Flex Real-Time PCR System (Applied Biosystems, Foster City, CA). Cycling conditions were $95^{\circ} \mathrm{C}$ for $2 \mathrm{~min}, 40$ cycles of $95^{\circ} \mathrm{C}$ for $30 \mathrm{~s}$ and $60^{\circ} \mathrm{C}$ for $30 \mathrm{~s}$, with the threshold set to automatic. The second testing laboratory performed real-time PCR assays in a QuantStudio 3 Real-Time PCR system (Applied Biosystems) using the PrimeTime Gene Expression Master Mix (IDT) with ROX as a passive reference dye. Cycling parameters and primer amounts were the same as in the method development lab.

LAMP. LAMP reactions were carried out with a total volume of $25 \mu \mathrm{l}$ containing $0.2 \mu \mathrm{M}$ each of primers 166_F3 and 166_B3, $1.6 \mu \mathrm{M}$ each of primers 166_FIP and 166_BIP and $0.8 \mu \mathrm{M}$ of primer 166_LoopF, $15 \mu \mathrm{l}$ of Isothermal Master Mix Iso-001 (Optigene, Horsham, UK), $3 \mu \mathrm{l}$ of molecular grade water, and $2 \mu \mathrm{l}$ of template DNA. The LAMP assay was run at $65^{\circ} \mathrm{C}$ for $30 \mathrm{~min}$ with a preheat step at $65^{\circ} \mathrm{C}$ for $1 \mathrm{~min}$ (Genie III, Optigene). Threshold was set at 
0.02 fluorescence ratio for the amplification rate (derivative of amplification curve).

Determination of limit of detection, linearity, and amplification efficiency. Isolate $\mathrm{Xvv} 681$ and pathotype strain SAM119 (syn. Xcz 416) were grown in nutrient broth at $30^{\circ} \mathrm{C}$ with shaking for $24 \mathrm{~h}$. Tenfold and half-log dilutions spanning a five-log range were prepared using sterile water and incubated at $95^{\circ} \mathrm{C}$ for $10 \mathrm{~min}$ in a thermomixer (Eppendorf, Hamburg, Germany). Two microliters from each dilution were used as a template in the realtime PCR assays and run in triplicate. Prior to heat treatment, aliquots from the $10^{-4}, 10^{-5}, 10^{-6}$, and $10^{-7}$ dilutions were spreadplated on nutrient agar plates and incubated at $30^{\circ} \mathrm{C}$ overnight to determine colony forming units (CFU) per ml. Standard curves were constructed relating $\mathrm{CFU}$ to $\mathrm{Ct}$ values, and limit of detection, linearity, and amplification efficiency were determined. Three different strains of $X$. vasicola $\mathrm{pv}$. vasculorum were used and each dilution was run in triplicate.

To evaluate any plant matrix effect, tenfold serial dilutions of the heat-treated cultures were prepared in DNA extracted from healthy corn leaves (DNeasy Plant Mini Kit, Qiagen), and realtime PCRs were set up as previously described, in duplicate. Limits of detection, linearity, and amplification were determined and compared with those dilutions in water.

PMA seed wash assay. Corn seeds were soaked for $8 \mathrm{~h}$ in phosphate buffered saline (PBS)-buffer with $10^{8} \mathrm{CFU} / \mathrm{ml} X$. vasicola pv. vasculorum in a $10^{\circ} \mathrm{C}$ cold room, dried on screens in a stack dryer to $11 \%$ moisture with room temperature air $\left(22\right.$ to $\left.24^{\circ} \mathrm{C}\right)$, and stored at room temperature for 9 months prior to use. After storage, 15 seeds were washed in $10 \mathrm{ml}$ of PBS for $4 \mathrm{~h}$ with gentle agitation, after which three 1-ml aliquots were removed from each seed wash and each treated with a different DNA extraction protocols. In the first protocol, cells were pelleted by centrifugation for $2 \mathrm{~min}$ at $14,000 \times g$, suspended in $400 \mu \mathrm{l}$ of PBS plus $100 \mu \mathrm{l}$ of $5 \times$ PMA Enhancer for Gram negative bacteria, and treated with $50 \mu \mathrm{M}$ PMA following the manufacturer's protocol (Biotium, Hayward, CA) including room temperature incubation in the dark for $10 \mathrm{~min}$ with agitation (700 rpm in thermomixer, Eppendorf), $15 \mathrm{~min}$ in a light box (PMA-Lite LED Photolysis device, Biotium), centrifugation for $5 \mathrm{~min}$ at $5,000 \times g$ to pellet cells and remove supernatant and DNA extraction by the standard protocol of a Soil Extraction kit using buffer 1 (Macherey-Nagel, Düren, Germany). In the second protocol, DNA was extracted by pelleting cells for $2 \mathrm{~min}$ at $14,000 \times g$ and suspending in lysis buffer with no prior PMA treatment (no PMA treatment). In the third protocol, serial dilutions were prepared and plated on nutrient agar to determine CFU/ml. PMA and non-PMAtreated seed washes were used as template for real-time PCR and LAMP assays as described previously. Experiments were repeated three times, and qPCRs run in triplicate. For negative controls, strains $\mathrm{Xvv} 715$ and $\mathrm{Xvv} 681$ were grown overnight in nutrient broth at $30^{\circ} \mathrm{C}$. One milliliter of overnight culture was transferred to a $1.5-\mathrm{ml}$ tube and incubated for $10 \mathrm{~min}$ at $95^{\circ} \mathrm{C}$, shaking at $700 \mathrm{rpm}$ in a thermomixer (Eppendorf). Cells proceeded through the DNA extraction protocols as described for the seed washes. Each DNA extraction was tested by qPCR in duplicate.

\section{RESULTS}

The genomes of U.S. corn isolates clustered within a subgroup of the $X$. vasicola pv. vasculorum clade based on REALPHY analysis (Fig. 1). A genome comparison of the historical isolate SAM119 to the $X$. vasicola pv. vasculorum sugarcane reference strain NCPBB 1326 revealed a unique 721-bp region in the SAM119 genome. BLAST analyses confirmed the 721 bp region was also present in isolates $\mathrm{Xvv}$ 645, $\mathrm{Xvv}$ 681, $\mathrm{Xvv} 715$, and Xvv NE744. No corresponding match for this region was found in the $X$. vasicola $\mathrm{pv}$. holcicola, $X$. campestris pv. arecae, $X$. vasicola, or $X$. campestris $\mathrm{pv}$. musacearum genomes available in GenBank at the time (Fig. 2). The 721-bp region contains the terminal end of a predicted filamentous hemagglutinin $\mathrm{N}$-terminal domain containing protein, and primers and probe were designed to the coding region for both TaqMan qPCR (qPCR 4909) and LAMP (LAMP 166) assays (Table 1). A complete genome of SAM119 and three draft genomes of Xvv 645, Xvv 681, and Xvv 715 were deposited to NCBI as a result of this study.

The qPCR 4909 and LAMP 166 assays were validated against positive and negative environmental (leaf) DNA samples and a culture collection. The qPCR 4909 assay correctly identified the positive (18/18) and negative (0/14) leaf samples from nine different states. The LAMP 166 assay identified all but one low titer leaf sample (17/18) and none of the negative samples $(0 / 14)$. The culture collection consisted of 31 out-group strains. The two assays were evaluated against 27 different Xanthomonas species or pathovars, $D$. solani, and a $R$. solanacearum strain. No off-target organisms were detected (Supplementary Table S1).

The assays were tested for limit of detection and efficiency. Additionally, the qPCR 4909 assay was tested for matrix effects in water and corn backgrounds (DNA from corn leaf). The efficiency of the assay was between 90 to $93 \%$ in water and near $100 \%$ in the corn background (Fig. 3). The limit of detection was approximately $1 \times 10^{3} \mathrm{CFU} / \mathrm{ml}$ in water and $2 \times 10^{3} \mathrm{CFU} / \mathrm{ml}$ in the corn DNA background. The semiquantitative LAMP 166 assay had a limit of detection near $1 \times 10^{4} \mathrm{CFU} / \mathrm{ml}$ in a water background to mimic bacterial streaming conditions (Table 2). Detection time ranged from $5 \mathrm{~min}$ for the high concentrations to 11 to $15 \mathrm{~min}$ for the low concentrations.

A live/dead cells distinction assay was developed to accompany the molecular diagnostics of seeds. PMA was added to seed wash exudate prior to DNA extraction. Cycle threshold $(\mathrm{Ct})$ values using the qPCR 4909 assay for non-PMA-treated samples were 25.506 $( \pm 0.071), 23.195( \pm 0.865)$, and $26.324( \pm 0.073)$, whereas with PMA treatment those values were $34.632( \pm 0.515), 32.491$ $( \pm 0.141)$, and 38.805 ( \pm 0.752 , two out of three technical replicates). Plating of the same seed wash estimated live bacterial populations of $3 \times 10^{3}, 3.2 \times 10^{4}$, and $1.01 \times 10^{3} \mathrm{CFU} / \mathrm{ml}$ remaining after treatment, respectively. Using the LAMP 166 assay, detection times without PMA were at 05:45, 05:15, and 05:45 min:s, whereas with PMA the values were slightly delayed at 08:30, 08:30, and 12:30, respectively. Additionally, cells were grown overnight, heat treated, and then treated either with or without PMA prior to DNA extraction. $\mathrm{Ct}$ values using the qPCR 4909 assay of non-PMAtreated cells were $20.569( \pm 0.050)$ and $20.531( \pm 0.001)$, whereas with PMA treatment the values were $34.742( \pm 0.014)$ and 39.434 (one replicate only).

A second laboratory tested the qPCR 4909 assay using isolates from their collection. The qPCR buffer was different, but they correctly detected 41 of $41 X$. vasicola pv. vasculorum strains from corn from multiple U.S. states and Argentina. Thirty-one additional out-group bacterial pathogens were tested, with one Pantoea sp. and two unknowns giving $\mathrm{Ct}$ values between 30 and 35. Twelve outgroup isolates produced $\mathrm{Ct}$ values between 35 and 40, but the target strains were well below a Ct of 30 (Supplementary Table S2).

\section{DISCUSSION}

The causal agent of corn bacterial leaf streak, Xanthomonas vasicola pv. vasculorum, has recently emerged in the United States, Argentina, and Brazil (Korus et al. 2017; Leite et al. 2019; Plazas et al. 2018; E. Sagata et al., unpublished data). In this study, we completed the genome of the South African pathotype strain, SAM119 (Lang et al. 2017) and contributed three draft genomes of U.S. isolates to public databases. Additionally, with whole-genome single nucleotide polymorphism phylogenetic analysis, we were able to further delineate the $X$. vasicola clade into groups that correspond with pathogenicity data. Interestingly, the corn isolates found in the United States and SAM119 formed a subgroup within the $X$. vasicola $\mathrm{pv}$. vasculorum clade, consistent with other findings 


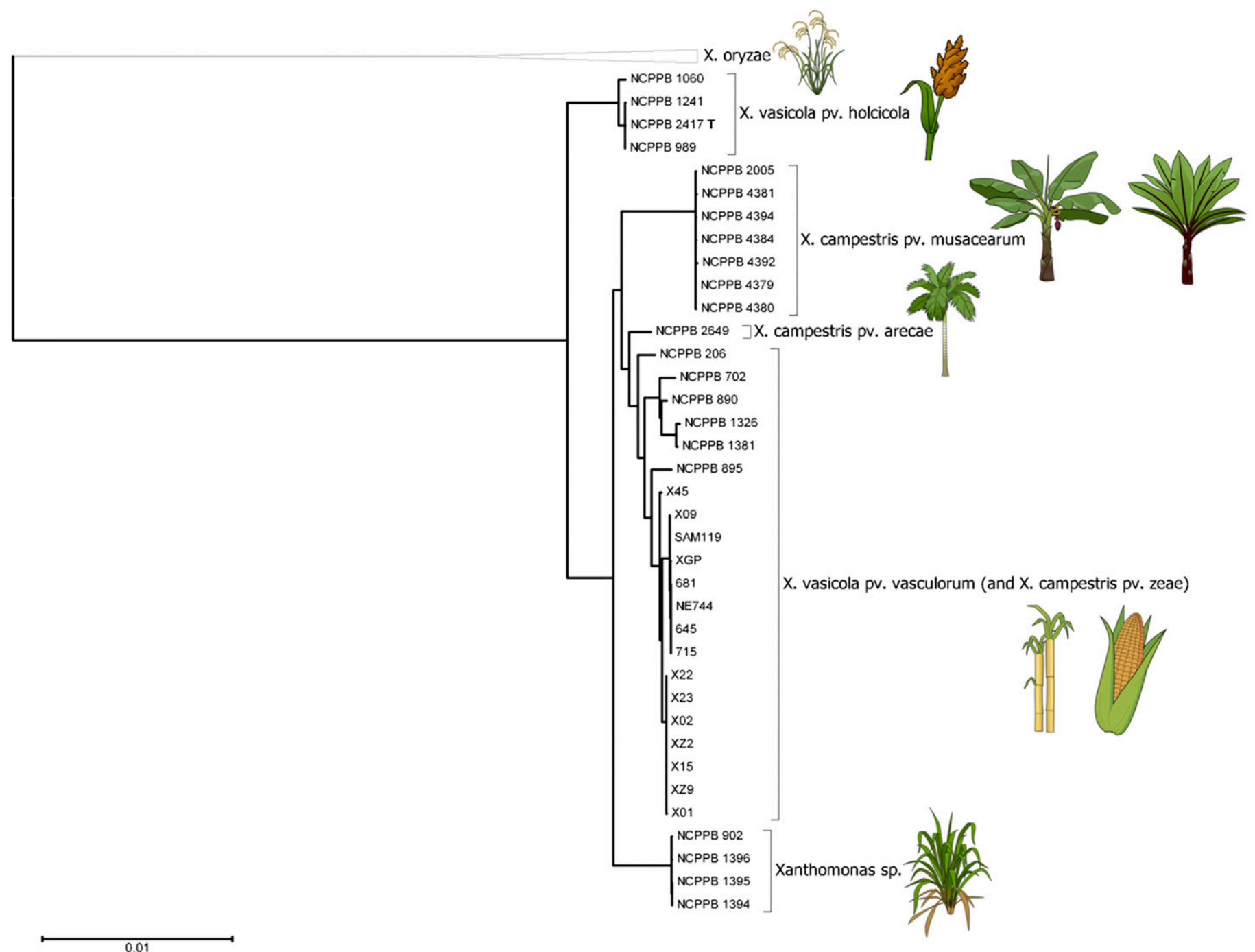

Fig. 1. Single nucleotide polymorphism-based phylogenetic analysis of Xanthomonas vasicola and closely related Xanthomonas strains using the program REALPHY. The U.S. isolates (681, NE744, 645, and 715) cluster with SAM119, historically X. campestris pv. zeae, within the X. vasicola pv. vasculorum clade. A clade from X45 to X01 contains all X. campestris pv. zeae-like strains but not all strains isolated corn, as NCPPB 206 does not cluster. Similarly, NCPPB 895 , isolated from sugarcane, groups closer to corn strains than sugarcane. The other $X$. vasicola strains clustered with strains isolated from similar hosts.

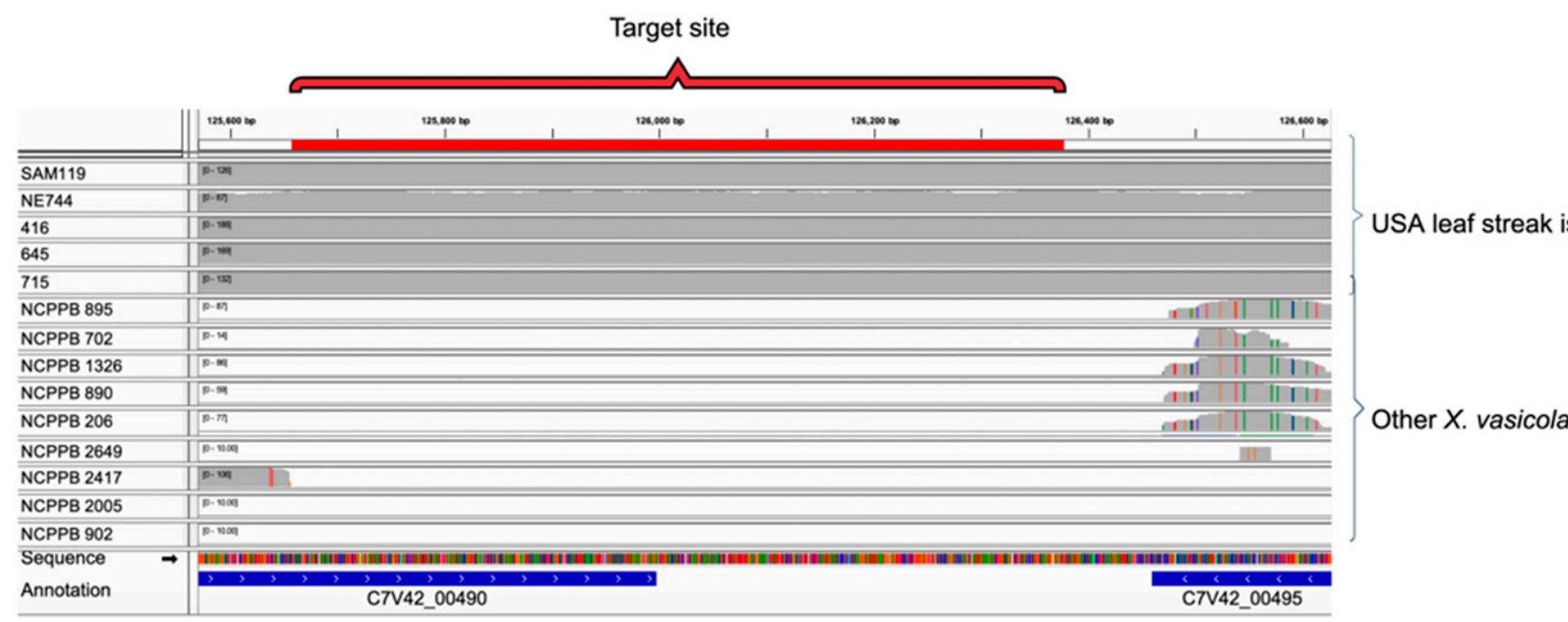

Fig. 2. The 721-bp target genomic sequence is absent from other Xanthomonas vasicola genomes. The image shows part of an alignment of Illumina genomic shotgun sequencing reads aligned against the reference sequence of the SAM119 chromosome (GenBank CP028127.1). Each bacterial strain is represented by a panel containing a plot of coverage depth along the genome. The target region corresponds to positions 125,656 to 126,376 and is highlighted in red. The range of depths (i.e., the scale of the y-axis) is indicated for each bacterial strain toward the left of the plots in square brackets. The positions of two protein-coding genes are indicated along the bottom of the plot. These are locus tag C7V42_00490, predicted to encode a large protein containing hemagglutination activity domains, and locus tag C7V42_00495, predicted to encode type I toxin-antitoxin system SymE family toxin. 
(G. Wu et al., unpublished data). This grouping informed the comparative genomics to mine the genomes for specific sequences to identify these particular strains (formerly X. campestris pv. zeae). We focused on a specific sequence that includes the $3^{\prime}$ end of a predicted filamentous hemagglutinin (FHA) N-terminal domaincontaining protein for detection assay design (Fig. 2). FHA proteins can mediate bacterial adherence and colonization, suggesting a potential functional role for this sequence and one that could remain conserved (Relman et al. 1989). Rapid TaqMan qPCR and LAMP assays were designed to this sequence for the specific detection of these strains.

A PCR protocol consisting of two independent reactions was previously developed for the detection of $X$. vasicola $\mathrm{pv}$. vasculorum (Lang et al. 2017). The two assays, in combination, specifically detected all strains in the $X$. vasicola pv. vasculorum clade, including those strains which infect sugarcane. Our goal was to specifically detect only the strains known historically as X. campestris pv. zeae, and furthermore do so on a qPCR platform. Attempts to convert the thirty-cycle PCR reactions (Lang et al. 2017) to forty-cycle qPCR reactions for increased sensitivity resulted in off-target effects, which led us to perform comparative genomics to identify a new target region for assay development. In silico analysis indicates that the 721-bp unique region is conserved in the newly released $X$. vasicola pv. zeae genomes from South Africa (Sanko et al. 2018), and the two assays should therefore detect all strains between X45 and X01 in the phylogenetic tree (Fig. 1).

The objective of this study was to develop tools for detection and diagnostics, not to address taxonomy, which is discussed elsewhere (Lang et al. 2017; Studholme et al. 2019). Nevertheless, our results do confirm the presence of a monophyletic clade encompassing the recent U.S. corn isolates along with historical " $X$. campestris pv. zeae" strains. Furthermore, our results confirm that this cornassociated clade falls within the radiation of strains classified as
$X$. vasicola pv. vasculorum isolated from sugarcane and (in the case of NCPPB 206) corn. In other words, these strains causing severe disease on corn should be considered a sublineage within the diversity of $X$. vasicola pv. vasculorum. There is no phylogenetic basis for splitting them into a separate taxon (X. vasicola pv. zeae); furthermore, their overlapping host-ranges further undermines any case for taxonomic splitting $X$. campestris pv. zeae away from $X$. vasicola pv. vasculorum. The molecular assays designed in this study, however, can distinguish this sublineage from other $X$. vasicola pv. vasculorum strains.

The qPCR 4909 and LAMP 166 assays successfully discriminated positive from negative samples. The qPCR 4909 assay was tested against a bacterial culture collection in the method development lab and another culture collection in a second testing laboratory. The assay remained specific in determining positive and negative screenings in two different labs. The higher rate of $\mathrm{Ct}$ values in the mid to upper 30 s by the second testing lab could be due to the different master mix and machine used. Attempts to use the same master mix were unsuccessful across platforms. Because the qPCR 4909 assay

TABLE 2. Loop-mediated isothermal amplification assay run on serial dilutions of Xanthomonas vasicola pv. vasculorum cells from SAM119 and Xvv $681^{\mathrm{a}}$

\begin{tabular}{lcc}
\hline CFU/ml & $\begin{array}{c}X . \text { vasicola } \text { pv. } \\
\text { vasculorum \% detected }\end{array}$ & $\begin{array}{c}\text { Average time } \\
\text { (min:s) }\end{array}$ \\
\hline $10^{7}-10^{8}$ & $100(4 / 4)$ & $5: 15$ \\
$10^{6}-10^{7}$ & $100(14 / 14)$ & $5: 43$ \\
$10^{5}-10^{6}$ & $100(26 / 26)$ & $7: 29$ \\
$10^{4}-10^{5}$ & $96(25 / 26)$ & $11: 12$ \\
$10^{3}-10^{4}$ & $29(7 / 24)$ & $15: 38$ \\
0 & $0(0 / 14)$ & $\mathrm{n} / \mathrm{a}$
\end{tabular}

a Total detected samples for each log range of cell concentrations were reported as percent detected.

TABLE 1. Primers and probe sequence and target for TaqMan PCR and loop-mediated isothermal amplification (LAMP)

\begin{tabular}{llcc}
\hline Primer & \multicolumn{1}{c}{ Sequence 5'-3' } & Amplicon size (bp) & Target \\
\hline $\begin{array}{c}\text { Real-time PCR } \\
\text { 4909_F }\end{array}$ & CTTCTATCTTGGATCCGTCGG & 139 & $\begin{array}{c}\text { Filamentous hemagglutinin N-terminal } \\
\text { domain-containing protein }\end{array}$ \\
4909_R & GCGGGAATATTAAATCTGGCG & & Filamentous hemagglutinin N-terminal \\
4909_probe & I56-FAM/ATT AAG CGC /ZEN/GGC ATC TGT CAA CC/3IABkFQ/ & & domain-containing protein \\
LAMP & & & \\
166_F3 & TTGGATCCGTCGGAAGTC & & \\
166_B3 & CGGAAGTTCAGTAAGCAAGA & & \\
166_FIP & GCCGCGCTTAATGATTCATTTGATTCCTTGACAACATCTGGATT & \\
166_BIP & CCTGTGCCGCCAGATTTTAACAGGCTTACCACTCAGTTG & & \\
166_loopF & GAAAATTTCTGGCGGAAAGTTAACG & & \\
\hline
\end{tabular}

A

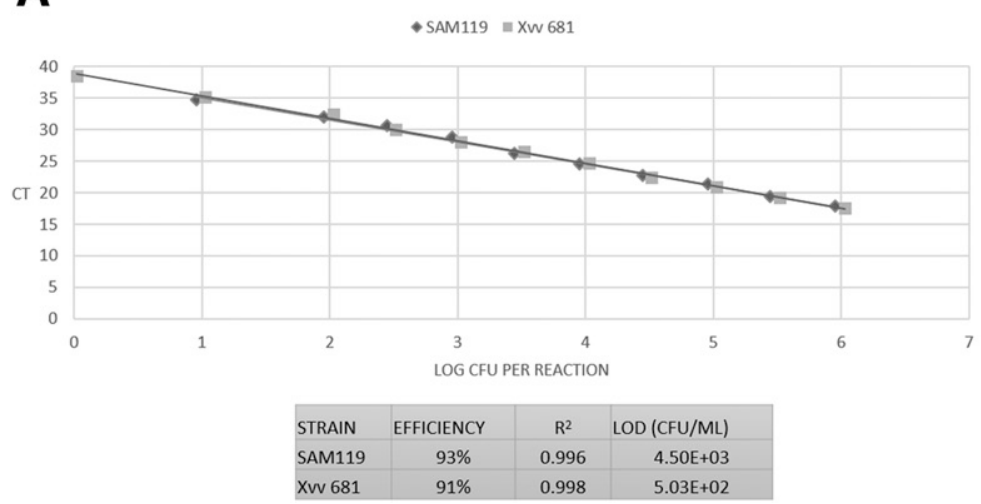

\section{B CORN DNA BACKGROUND}
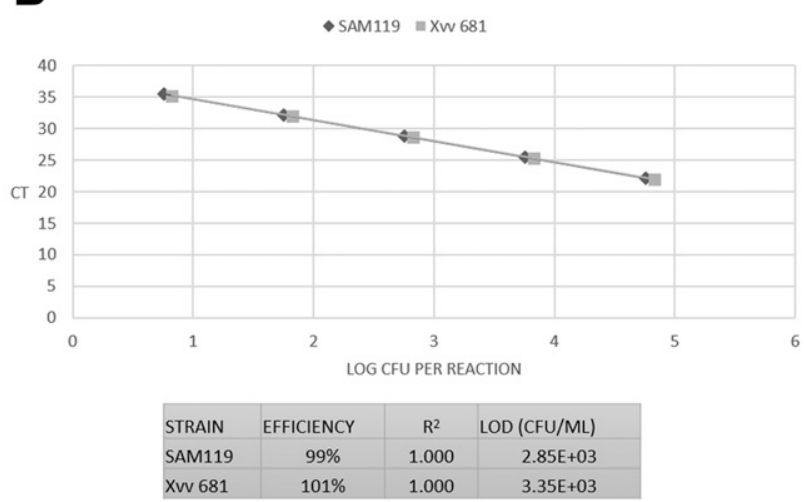

Fig. 3. TaqMan qPCR assay run on serial dilutions of Xanthomonas vasicola pv. vasculorum cells from SAM119 and Xvv 681. A, Serial dilution with a water background with calculated efficiency, $R^{2}$ value, and limit of detection (LOD). B, Serial dilution with corn leaf total DNA extract as a background with calculated efficiency, $R^{2}$ value, and LOD. All data points are an average of three technical replicates. 
was run on pure cultures, it was easy to define a lower $\mathrm{Ct}$ threshold for true positive samples in the second testing laboratory. We recommend using a Ct cutoff of 30 when testing pure cultures. The qPCR 4909 assay also successfully detected samples extracted from corn leaf material with varying titers. Based on the detection limit experiments and the results from the environmental samples, we recommend establishing a $\mathrm{Ct}$ cutoff of 37 when testing total extracted DNA with a corn background. The LAMP 166 assay was only tested in the method development lab. A threshold of 0.02 was used to reduce false-positive values that sometimes occur early in a LAMP reaction.

The assays developed here can be used by diagnostic laboratories and researchers alike to quickly identify the $X$. vasicola $\mathrm{pv}$. vasculorum strains that have historically produced more severe symptoms on corn. Moreover, incorporating PMA into the DNA extraction protocol from seed wash provided an effective method to quickly determine live versus dead cells using qPCR. This protocol may be useful to measure viable levels of $X$. vasicola $\mathrm{pv}$. vasculorum on seeds to determine whether it meets a biologically relevant, predetermined threshold. The LAMP assay could be used following bacterial streaming and is portable, allowing potential use outside of the laboratory.

\section{ACKNOWLEDGMENTS}

We thank Jillian Lang and Jan Leach for scientific discussions and providing strains for testing, and everyone involved in the 2016 corn field survey for bacterial leaf streak.

\section{LITERATURE CITED}

Ah-You, N., Gagnevin, L., Grimont, P. A., Brisse, S., Nesme, X., Chiroleu, F., Ngoc, L. B. T., Jouen, E., Lefeuvre, P., and Vernière, C. 2009. Polyphasic characterization of xanthomonads pathogenic to members of the Anacardiaceae and their relatedness to species of Xanthomonas. Int. J. Syst. Evol. Microbiol. 59:306-318.

Altschul, S. F., Gish, W., Miller, W., Myers, E. W., and Lipman, D. J. 1990. Basic local alignment search tool. J. Mol. Biol. 215:403-410.

Bankevich, A., Nurk, S., Antipov, D., Gurevich, A. A., Dvorkin, M., Kulikov, A. S., Lesin, V. M., Nikolenko, S. I., Pham, S., and Prjibelski, A. D. 2012. SPAdes: A new genome assembly algorithm and its applications to singlecell sequencing. J. Comput. Biol. 19:455-477.

Bertels, F., Silander, O. K., Pachkov, M., Rainey, P. B., and van Nimwegen, E. 2014. Automated reconstruction of whole-genome phylogenies from shortsequence reads. Mol. Biol. Evol. 31:1077-1088.

Boehland, P. 2016. Statement on Xanthomonas vasicola pv. vasculorum. U.S. Department of Agriculture, Animal and Plant Health Inspection Service. https://www.aphis.usda.gov/aphis/newsroom/news/sa_by_date/ newsroom-2016/sa-08/statement-corn-xvv

Coutingo, T. A., and Wallis, F. M. 1991. Bacterial streak disease of maize (Zea mays L.) in South Africa. J. Phytopathol. 133:112.

Kearse, M., Moir, R., Wilson, A., Stones-Havas, S., Cheung, M., Sturrock, S., Buxton, S., Cooper, A., Markowitz, S., and Duran, C. 2012. Geneious Basic: An integrated and extendable desktop software platform for the organization and analysis of sequence data. Bioinformatics 28: 1647-1649.
Korus, K., Lang, J., Adesemoye, A., Block, C., Pal, N., Leach, J., and Jackson-Ziems, T. 2017. First report of Xanthomonas vasicola causing bacterial leaf streak on corn in the United States. Plant Dis. 101:1030.

Lang, J., DuCharme, E., Ibarra Caballero, J., Luna, E., Hartman, T., Ortiz-Castro, M., Korus, K., Rascoe, J., Jackson-Ziems, T., and Broders, K. 2017. Detection and characterization of Xanthomonas vasicola pv. vasculorum (Cobb 1894) comb. nov. causing bacterial leaf streak of corn in the United States. Phytopathology 107:1312-1321.

Leite, R., Jr., Custódio, A., Madalosso, T., Robaina, R., Duin, I., and Sugahara, V. 2019. First report of the occurrence of bacterial leaf streak of corn caused by Xanthomonas vasicola pv. vasculorum in Brazil. Plant Dis. 103:145.

Li, H., and Durbin, R. 2009. Fast and accurate short read alignment with Burrows-Wheeler transform. Bioinformatics 25:1754-1760.

Li, H., Handsaker, B., Wysoker, A., Fennell, T., Ruan, J., Homer, N., Marth, G., Abecasis, G., and Durbin, R. 2009. The sequence alignment/map format and SAMtools. Bioinformatics 25:2078-2079.

Parkinson, N., Aritua, V., Heeney, J., Cowie, C., Bew, J., and Stead, D. 2007. Phylogenetic analysis of Xanthomonas species by comparison of partial gyrase B gene sequences. Int. J. Syst. Evol. Microbiol. 57:2881-2887.

Plazas, M., De Rossi, R., Brücher, E., Guerra, F., Vilaró, M., Guerra, G., Wu, G., Ortiz-Castro, M., and Broders, K. 2018. First report of Xanthomonas vasicola pv. vasculorum causing bacteria leaf streak of maize (Zea mays) in Argentina. Plant Dis. 102:1026.

Qhobela, M., and Claflin, L. 1992. Eastern and southern African strains of Xanthomonas campestris pv. vasculorum are distinguishable by restriction fragment length polymorphism of DNA and polyacrylamide gel electrophoresis of membrane proteins. Plant Pathol. 41:113-121.

Qhobela, M., Claflin, L., and Nowell, D. 1990. Evidence that Xanthomonas campestris pv. zeae can be distinguished from other pathovars capable of infecting maize by restriction fragment length polymorphism of genomic DNA. Can. J. Plant Pathol. 12:183-186.

Relman, D. A., Domenighini, M., Tuomanen, E., Rappuoli, R., and Falkow, S. 1989. Filamentous hemagglutinin of Bordetella pertussis: Nucleotide sequence and crucial role in adherence. PNAS 86:2637-2641.

Sanko, T. J., Kraemer, A. S., Niemann, N., Gupta, A. K., Flett, B. C., Mienie, C., and Bezuidenhout, C. C. 2018. Draft genome assemblages of 10 Xanthomonas vasicola pv. zeae strains, pathogens causing leaf streak disease of maize in South Africa. Genome Announc. 6:e00532-e00518.

Studholme, D. J., Wicker, E., Aspin, A., Bogdanove, A., Broders, K., Dubrow, Z., Grant, M., Jones, J. B., Karamura, G., and Lang, J. 2019. Transfer of Xanthomonas campestris pv. arecae, and Xanthomonas campestris pv. musacearum to Xanthomonas vasicola (Vauterin) as Xanthomonas vasicola pv. arecae comb. nov., and Xanthomonas vasicola pv. musacearum comb. nov. and description of Xanthomonas vasicola pv. vasculorum pv. nov. bioRxiv 571166.

Stulberg, M. J., Shao, J., and Huang, Q. 2015. A multiplex PCR assay to detect and differentiate select agent strains of Ralstonia solanacearum. Plant Dis. 99:333-341.

Thorvaldsdóttir, H., Robinson, J. T., and Mesirov, J. P. 2013. Integrative Genomics Viewer (IGV): High-performance genomics data visualization and exploration. Brief. Bioinform. 14:178-192.

Vauterin, L., Hoste, B., Kersters, K., and Swings, J. 1995. Reclassification of Xanthomonas. Int. J. Syst. Evol. Microbiol. 45:472-489.

Vauterin, L., Yang, P., Hoste, B., Pot, B., Swings, J., and Kersters, K. 1992. Taxonomy of xanthomonads from cereals and grasses based on SDS-PAGE of proteins, fatty acid analysis and DNA hybridization. Microbiology 138: 1467-1477.

Walker, B. J., Abeel, T., Shea, T., Priest, M., Abouelliel, A., Sakthikumar, S., Cuomo, C. A., Zeng, Q., Wortman, J., and Young, S. K. 2014. Pilon: An integrated tool for comprehensive microbial variant detection and genome assembly improvement. PLoS One 9:e112963. 